\title{
Expression of Neutrophil Gelatinase-Associated Lipocalin and Kidney Injury Molecule-1 in Wilms Tumor
}

\author{
Senem ERSAVAŞ ${ }^{1}$, Gülden DiNIZ' ${ }^{1}$, Hülya TOSUN YILDIRIM², Yetkin KOCA', \\ Dudu SOLAKOĞLU KAHRAMAN', Duygu AYAZ', Bengü DEMIRAĞ³
}

\author{
'Department of Pathology, Tepecik Education and Research Hospital, IZMIR, TURKEY \\ Department of ${ }^{2}$ Pathology and ${ }^{3}$ Oncology, Dr. Behcet Uz Children's Hospital, IZMIR, TURKEY
}

\begin{abstract}
Objective: Neutrophil gelatinase-associated lipocalin (NGAL) and Kidney injury molecule-1 (KIM-1) play important roles in both immunity and cell proliferation. It was reported previously that they are overexpressed in various human cancers. The present study was undertaken to examine the expressions of NGAL and KIM-1 in Wilms Tumors.

Material and Method: Tissue samples of 50 Wilms Tumors were evaluated and underwent immunhistochemical staining for NGAL and KIM-1 protein expressions. The correlations between them, and some clinical prognostic factors such as tumor weight, stage and histological features were also evaluated.

Results: Twenty-three (46\%) of the cases were male while 27 (54\%) were female. The mean age was found to be $3.26 \pm 2$ years. The average tumor size was $9.16 \pm 2.9 \mathrm{~cm}$ in diameter and the average weight of the kidney was $478 \pm 312$ gr. Thirteen (26\%) cases were stage I, 18 (36\%) cases were stage II, 7 (14\%) cases were stage III, and $6(12 \%)$ cases were stage IV. Thirty-nine cases were alive (78\%), while 11 cases $(22 \%)$ were deceased. Mean overall survival time was $68.2 \pm 39.5$ (2-148) months. NGAL expression was negative in all tumors except the neutrophils within the tumors. KIM-1 expression was positive in 37 tumors (74\%), while it was absent in 13 tumors (26\%). Using Mann-Whitney U Analysis, KIM-1 expression was found to be associated with the stage of the tumor $(\mathrm{p}=0.027)$.
\end{abstract}

Conclusion: The preliminary data indicates that KIM-1 expression may be associated with stage in Wilms Tumor. However, further studies are needed to validate these pilot observations and to clarify the functional and mechanistic significance of this relevance.

Key Words: Wilms Tumor, NGAL protein, KIM-1 protein

\section{INTRODUCTION}

Wilms Tumor (WT) is the most common malignant renal tumor of children, accounting for approximately $14 \%$ of pediatric cancers (1). Although survival rates in WT have been improved in the past decades due to a multidisciplinary therapeutic approach, a certain population of the patients continue to experience poor survival and increased rates of relapse (2). Mutations and abnormal expressions of the 6 WT genes basically contribute to tumorigenesis of WT but other genes also participate in its development. Recent studies have revealed that several genetic abnormalities are associated with a worse prognosis in $\mathrm{WT}$, even in those with localized stage and favorable histology $(3,4)$.

Neutrophil gelatinase-associated lipocalin (NGAL), a member of the lipocalin superfamily, was first isolated as a $25 \mathrm{kDA}$ glycoprotein covalently bound to matrix metalloproteinase 9 (MMP9) in human neutrophils (5). Although initially in neutrophils, it was later found to be

(Turk Patoloji Derg 2016, 32:158-163)

Received : 04.01.2016 Accepted : 10.05.2016 expressed in most epithelial cells and to participate in the diverse processes of growth, development, differentiation and tumorigenesis of many tissues $(6,7)$.

Kidney injury molecule-1 (KIM-1) was first reported as a sensitive and specific biomarker in detecting injury of the proximal tubules in 1998 by Ichimura (8). KIM-1 is a type 1 membrane protein that contains a novel six-cysteine immunoglobulin-like domain and a mucin domain. Structurally, KIM-1 is a member of the immunoglobulin gene superfamily most reminiscent of mucosal addressin cell adhesion molecule 1 (MAdCAM-1). Human KIM-1 is also homologous to the monkey hepatitis A virus cell receptor 1 (HAVcr-1) (9). KIM-1 is expressed at a low level in the normal kidney but is increased dramatically in the post-ischemic kidney (8-10).

Hitherto, many parameters have been suggested as relevant markers for assessing the proliferative activity and tumor cell dynamics of WT (11-13). However, the presence

Correspondence: Gülden DINIIZ

Tepecik Eğitim ve Araştırma Hastanesi, Patoloji Bölümü, İZMİR, TURKEY

E-mail: agdiniz@gmail.com Phone: +90 2324696969 / 3791 
of NGAL and KIM-1 expressions in WT has not been investigated widely (10). The aim of this study was to explore the importance of these two markers in Wilms tumor and also to investigate the correlations between them, and some clinical prognostic factors such as tumor weight, stage and histological features.

\section{MATERIAL and METHODS}

WT resection specimens of 50 cases diagnosed and treated in Dr. Behçet Uz Children's Education and Research Hospital between 1999 and 2014 were included in this study. The study was approved by the Local Ethics Committee of Tepecik Education and Research Hospital. The staging system developed by the National Wilms Tumor Study Group (NWTS) was used to describe the extent of spread of these tumors $(14,15)$.

For immunohistochemistry (IHC), hematoxylin and eosin (H\&E) staining was used to select appropriate paraffin blocks and to identify the viable tumor areas. IHC was performed by the streptavidin biotin peroxidase method (Invitrogen, Camarillo, 85-9043). Serial 5- $\mu \mathrm{m}$ sections were obtained and these slides were baked over-night at $60^{\circ} \mathrm{C}$, dewaxed in xylene, and hydrated with distilled water through decreasing concentrations of alcohol. All slides were treated with heat-induced epitope retrieval in the microwave (in $10 \mathrm{mM} / \mathrm{L}$ citrate buffer, $\mathrm{pH} 6.0$, for 20 minutes, followed by cooling at room temperature for 20 minutes) and blocked for endogenous peroxidase and biotin. An affinity purified monoclonal mouse antibodies against NGAL (Novus Biologicals, Littleton, USA, NDP190331) and KIM-1 (Bioss, Philadelphia, USA, HAVCR1) were used at a dilution of 1: 300 . Renal tissue with acute

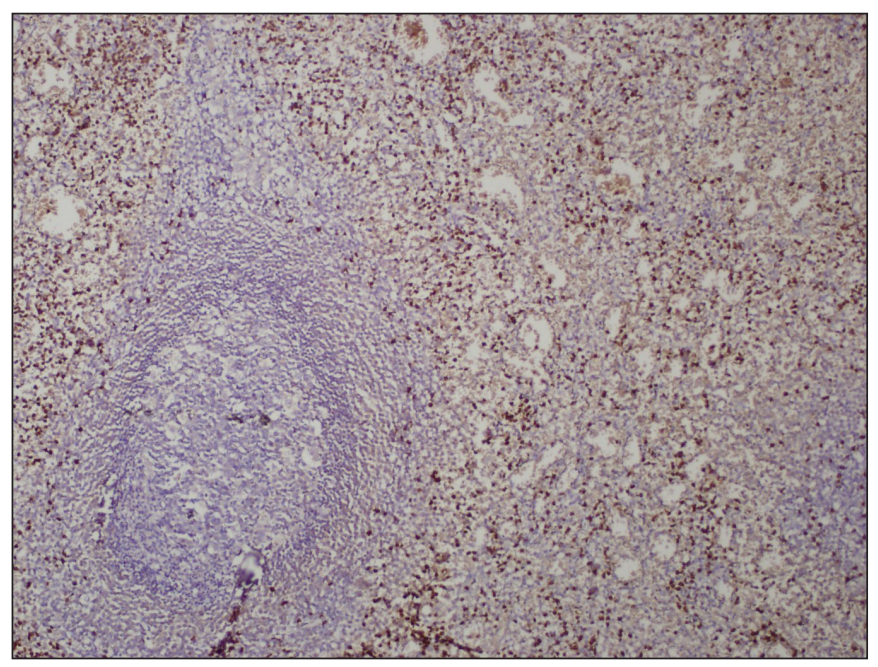

Figure 1: Cytoplasmic NGAL expression in red pulp of spleen (NGAL; x100). tubular necrosis was used as positive control for KIM-1 and splenic tissue for NGAL (Figure 1). The evaluation was blinded to any of the clinical features and staining patterns were classified according to the severity of staining. For KIM-1, cytoplasmic staining similar to the proximal tubules in control tissues was considered as positive (Figure 2). Focal staining occupying less than $5 \%$ of the field or diffuse weak staining were considered as negative. In previous studies, it was reported that NGAL showed both cytoplasmic and membranous expression in most tissues. Contrary to the other studies, there was no expression of NGAL in tumor cells. We counted the neutrophils that infiltrated the tumors. If there were up to five cells in every high power fields, we evaluated this as negative for NGAL. Spearman Correlation analysis, Mann-Whitney U test, Chi square test and Kaplan-Meier survival analyses were performed for statistical analysis with SPSS 15.0. P values less than 0.05 was considered to be statistically significant.

\section{RESULTS}

Surgery, chemotherapy and radiotherapy were the treatment modalities that were applied alone or in combination to the total of 50 patients according to their individual features. We used the NWTS protocol with surgery approach first for patients with unilateral tumor, but pre-operative chemotherapy was added and the combination of drugs was changed for patients with bilateral tumors. In addition, unfavorable histology required radiation therapy, even in some localized diseases. Therefore we classified the histology of all tumors as favorable or unfavorable. Thirtynine $(78 \%)$ cases had triphasic tumors, while 11 (22\%) were biphasic and the blastemal component was predominant.

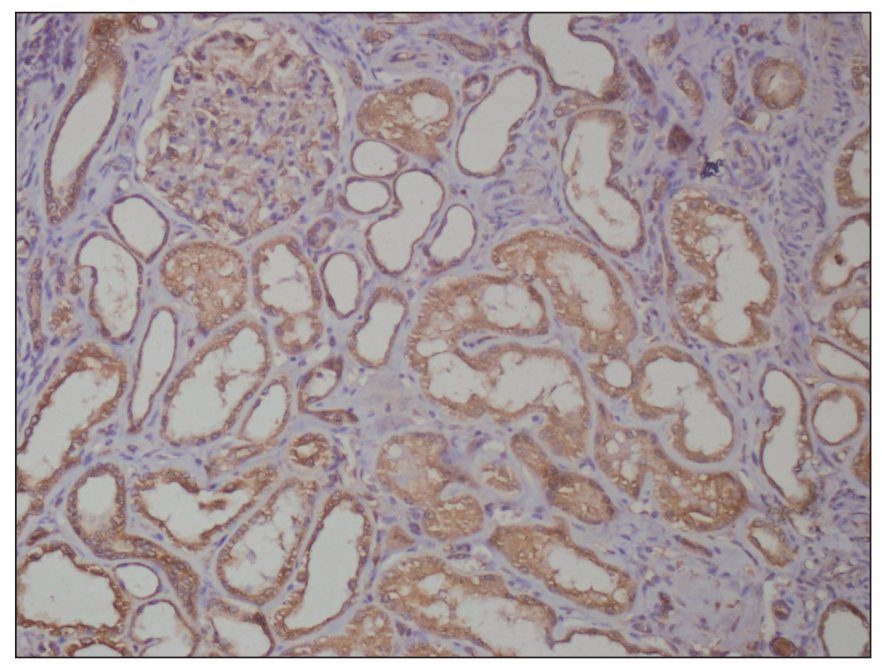

Figure 2: Cytoplasmic KIM-1 expression in proximal tubules of post-ischemic kidney (KIM-1; x200). 
These latter 11 cases were evaluated as showing unfavorable histology. In the whole series, 11 patients died at followup; 3 of these died because of bilateral tumor, and 4 from conditions apparently unrelated to WT such as pneumonia, sepsis, hepatic insufficiency and veno-occlusive disease.

Twenty-three (46\%) of the cases were male while 27 (54\%) were female. The mean age was found to be $3.26 \pm 2$ years (ranging from 5 months to 8 years). The tumor was rightsided in 25 (50\%) cases, left-sided in $19(38 \%)$ cases and $6(12 \%)$ cases had bilateral tumors (stage V). The average tumor size was $9.16 \pm 2.9 \mathrm{~cm}$ in diameter and the average weight of the kidney was $478 \pm 312$ gr (15). Thirteen (26\%) cases were stage I, 18 (36\%) cases were stage II, 7 (14\%) cases were stage III, 6 (12\%) cases were stage IV. Thirty-nine

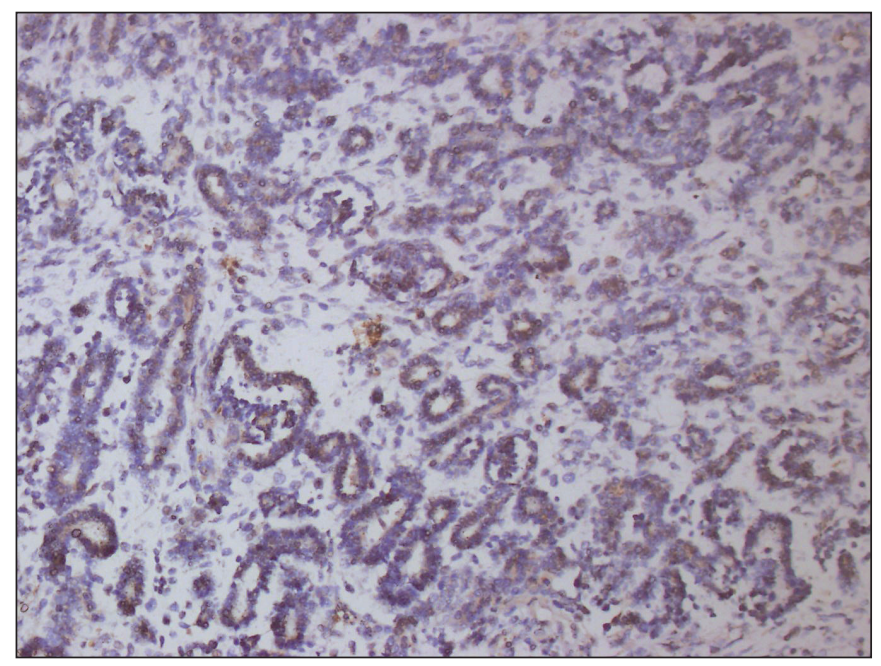

Figure 3: Cytoplasmic KIM-1 expression in epithelial component in WT (KIM-1; x200).

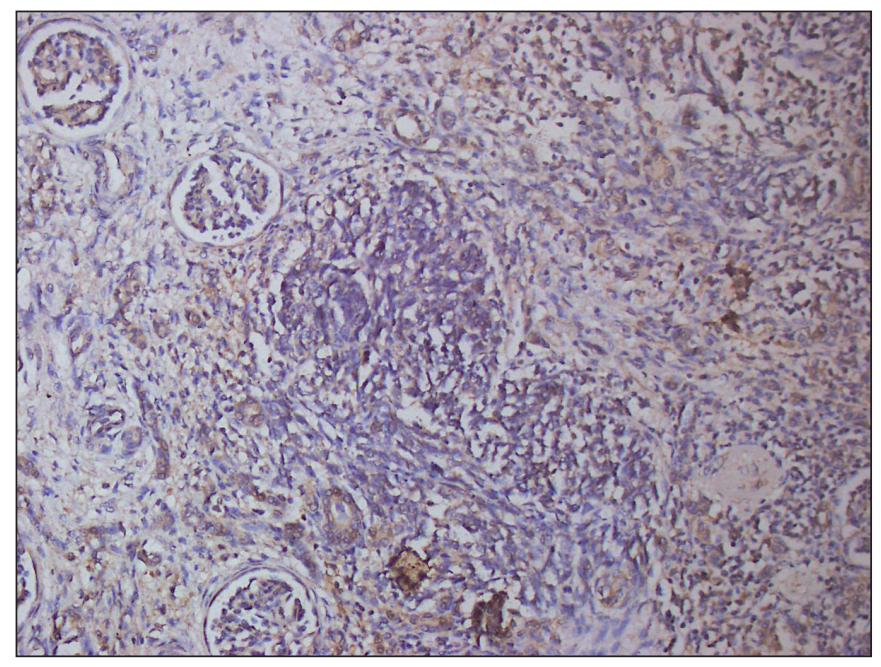

Figure 5: Diffuse KIM-1 expression in a triphasic WT (KIM-1; $\mathrm{x} 200)$. cases were alive (78\%), while 11 cases (22\%) were deceased. Mean overall survival time was $68.2 \pm 39.5$ (3-148) months.

The frequency of KIM-1 expression varied between different components in the same tumor. KIM-1 was negative in $13(26 \%)$ cases. Expression was limited in the epithelial component in 19 (38\%) cases (Figure 3), while it was limited in the blastemal in $7(14 \%)$ cases (Figure $4)$ and in mesenchymal areas in $3(6 \%)$ cases. In 8 cases (16\%), diffuse KIM-1 expressions were determined (Figure 5). NGAL expressions were determined in only NGALpositive inflammatory cells within the WTs (Figure 6). In most tumors, less than 5 NGAL-positive neutrophils per high-power field were determined. Therefore NGAL was considered as negative in all WTs.

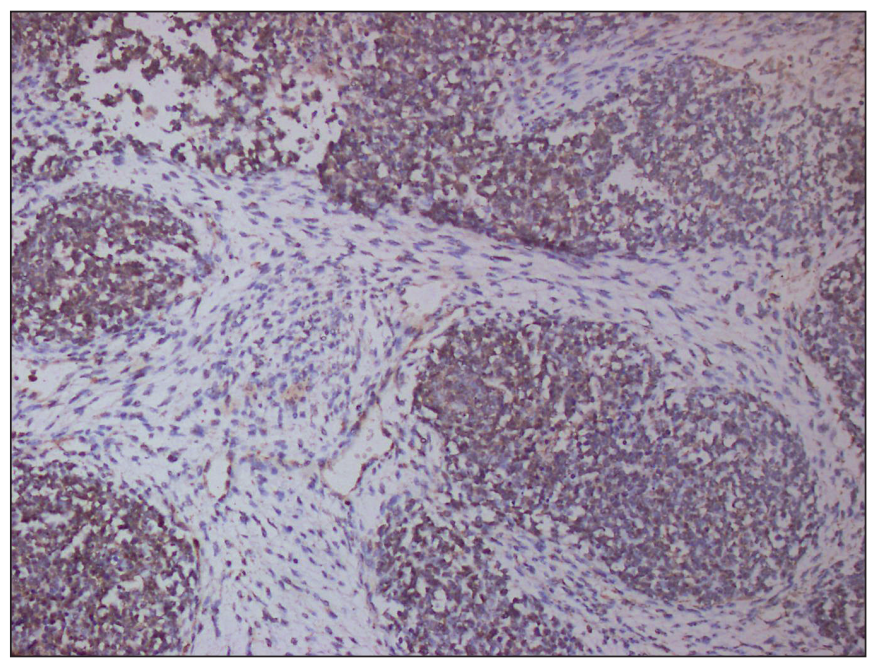

Figure 4: Cytoplasmic KIM-1 expression in blastemal component in WT (KIM-1; x100).

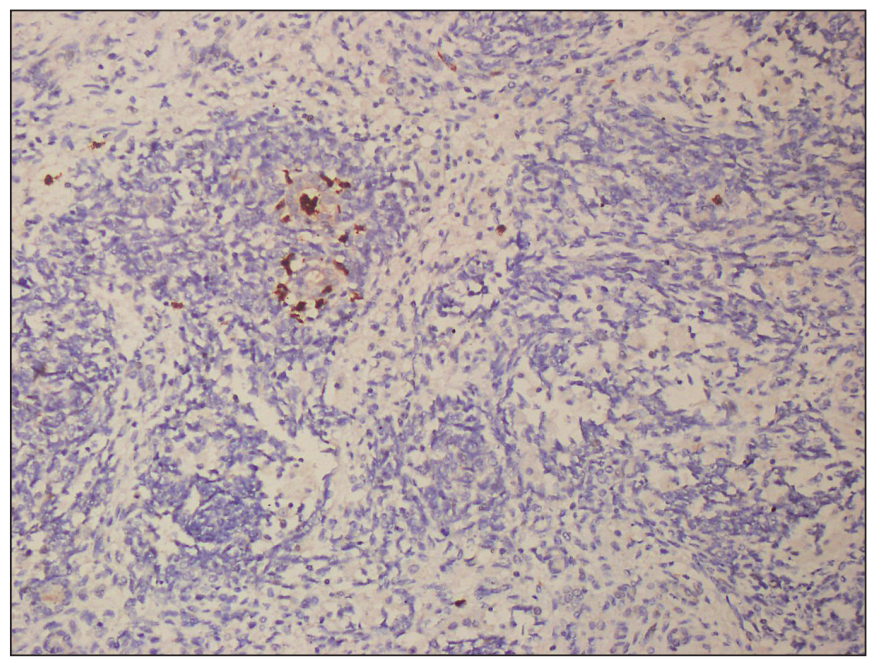

Figure 6: Note the NGAL-positive inflammatory cell within a WT (NGAL; x200). 
Most prognostic parameters such as kidney weight $(\mathrm{p}=0.127)$, tumor diameter $(\mathrm{p}=0,271)$, patient age $(\mathrm{p}=0.340)$ and therapy response $(\mathrm{p}=0.407)$ were not found to be associated with KIM-1 expression using the MannWhitney U and Chi-square Analyses. The overall survival was $61.5 \pm 11.7$ months in patients with KIM-1 positive tumors while it was $70.8 \pm 6.3$ months in KIM-1 negative tumors. There were no relationship between the KIM-1 expression and the survival (Log Rank, $\mathrm{p}=0.932$ ) by KaplanMeier Survival Analysis (Figure 7).

KIM-1 expression was positive in all stage I tumors and most stage II and III tumors. In contrast, KIM-1 was determined as negative in most stage IV tumors (Figure 8). While $67.5 \%$ of KIM-1 positive tumors were in the earlystage, $46.2 \%$ of KIM-1 negative tumors were in the early stage, excluding the bilateral tumors. The Chi square test revealed a relationship between KIM-1 expression and stage that was statistically significant $(p=0.027)$.

\section{DISCUSSION}

NGAL was initially defined as a useful bacteriostatic agent, and was found to be over-expressed in many types of cancers including breast, pancreatic and ovarian cancers $(5,6)$. The reported effects of NGAL in tumors are contradictory. For example, it was shown to have protumoral effects in breast (16), stomach (17) and esophageal cancers (18). In contrast, some studies showed that NGAL demonstrates antitumor and antimetastatic effect in anaplastic thyroid carcinoma cells (19), prostate cancer (20) and cholangiocarcinoma (21). Recently Wang et al. (22) reported that both NGAL gene and NGAL expression in tumor tissue was down-regulated

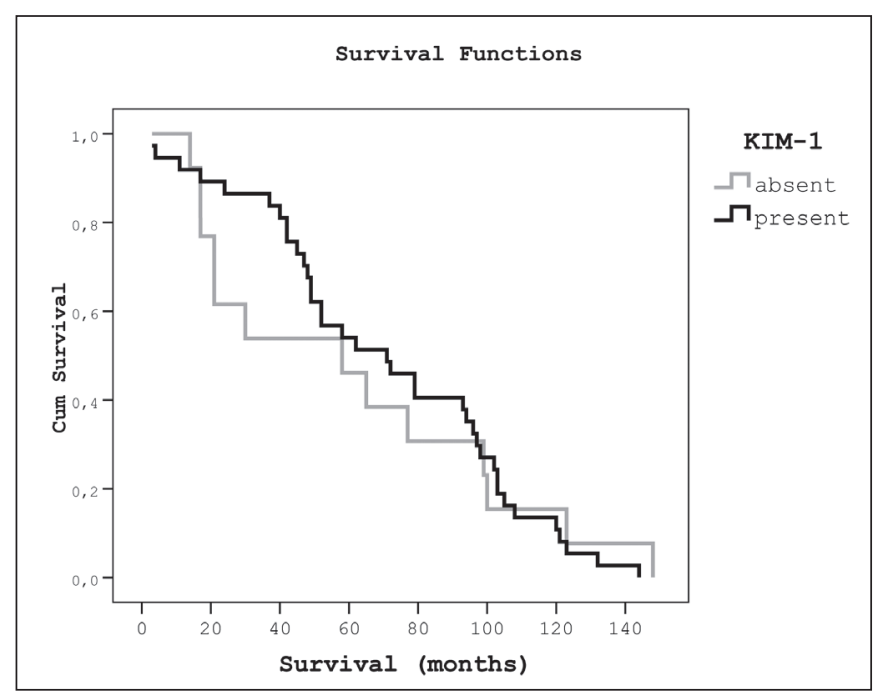

Figure 7: No statistical significant association with tumoral KIM1 expression and survival (Log Rank, $\mathrm{p}=0.932$ ). in head and neck squamous cell carcinoma (HNSCC) and this down-regulation may correlate with tumorigenesis in HNSCC. It was also reported that NGAL could form a complex with MMP-9 to prevent its degradation and increase MMP-9 activity. Moreover, NGAL is bound to siderophores and participates in iron metabolism in mammalians. Thus, iron homeostasis was speculated to be involved with NGAL in promoting cancer. Based on these studies, NGAL was speculated to be a new kind of metastasis biomarker. However, the detailed mechanism has not been totally understood yet (16-22). In the present study, we evaluated the NGAL expression in WT. However, we did not determine NGAL expression in tumor cells or renal tissue. Therefore, we think that NGAL may not have any role in tumorigenesis in WTs.

Clinical investigations have revealed that the prognosis of WT correlates with stage and favorable histology, which is characterized by the presence of all three histological elements and the absence of diffuse anaplasia $(12,14,15)$. These three histological components of WT have different proliferation potentials and different responses to therapy. Hitherto, many studies have revealed these differences. In most reports, the lowest proliferative capacity was determined in the mesenchymal component and this component generally survived after chemotherapy $(14,15)$. In the present study, KIM-1 expression was determined in the early stage tumors. In addition, we determined KIM1 expressions confined to the epithelial and blastemal components in the most cases. Our results have two important implications. Firstly, the relationship between the KIM-1 expression and stage suggests that KIM-1

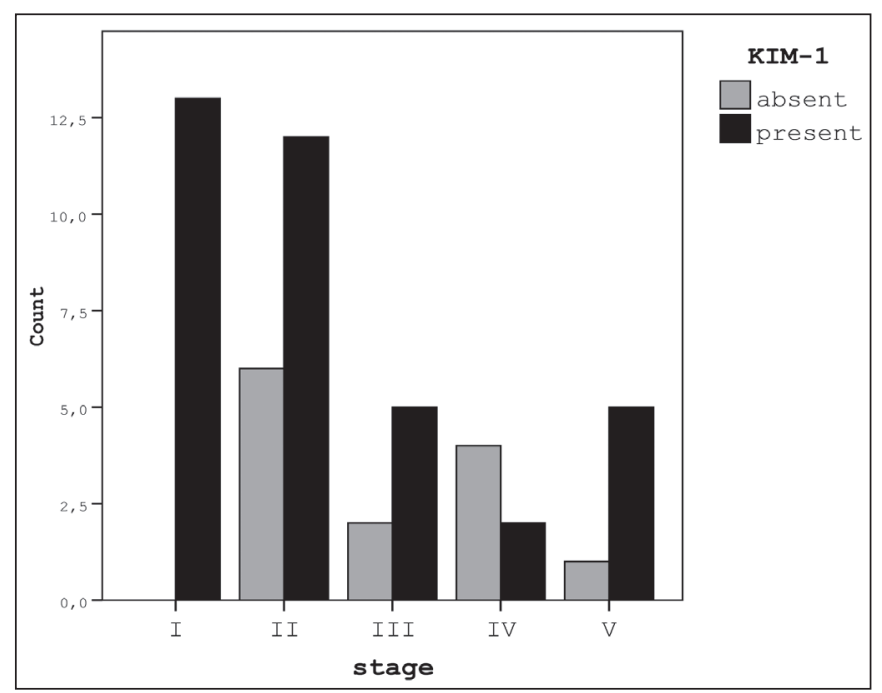

Figure 8: Significant association with tumoral KIM-1 expression and stage $(\mathrm{p}=0.027)$. 
may be used an important indicator of localized disease. Secondly, KIM-1 expression is potentially relevant in WT differentiation. However, further research is required to define how KIM-1 expression status can be used to clinical advantage in WT.

As in several body fluids, the urine is a rich reservoir of various substances and extracellular vesicles, directly originating from cells facing the urinary lumen. These substances are secreted by all types of cells under both physiological and pathological conditions. Some of them are accepted as markers of glomerular and tubular damage, as well as of renal regeneration. In addition, some substances appear to be involved in the cell-to-cell communication along the nephron and to emerge as potential amplifying or limiting factors in renal damage. Substances secreted from injured cells may favor the demonstration of fibrosis or disease progression. KIM-1 is one of these substances in the urine and it has been identified as representing an incredible source of information for diagnostic purposes (23). Several studies revealed that KIM-1 is expressed in both proliferating and dedifferentiated epithelial cells in regenerating proximal tubules. In addition, it is an epithelial cell adhesion molecule up-regulated in the cells, which are dedifferentiated and undergoing replication. KIM-1 may play an important role in the restoration of the morphological integrity and function to the post-ischemic kidney. KIM-1 is a sensitive and specific biomarker in detecting injury of proximal tubules in humans and other animals $(10,23,24)$. Recent studies indicate that KIM-1 may play an important role in the tumorigenesis of renal cell carcinomas $(10,24)$. Kidney development is a complex process regulated by transcription factors, proto-oncogenes, and several growth factors that act as signaling molecules and their receptors. WT can be considered as a failure of this transition (11). In this study, we determined KIM-1 expression in most WTs. This finding indicates that urinary KIM-1 may also be a marker in WTs. KIM-1, a marker of tubular damage, may possibly be useful to gain information about tissue damage, regeneration and even tumorigenesis in WTs.

In summary, the preliminary data indicates that KIM1 is frequently expressed in WT and this expression is negatively associated with stage in WTs. However, further studies are needed to validate these pilot observations and to clarify the functional and physiopathologic significance of this relevance. Contrary to the other studies, we did not determine any association with NGAL protein and tumorigenesis in WT.

\section{CONFLICT OF INTEREST}

The authors declared no conflict of interest

\section{REFERENCES}

1. An Q, Wang Y, An R, Li Y, Yao T, Zhai B, Sun X. Association of E2F3 expression with clinicopathological features of Wilms' tumors. J Pediatr Surg. 2013;48:2187-93.

2. Honeyman JN, Rich BS, McEvoy MP, Knowles MA, Heller G, Riachy E, Kobos R, Shukla N, Wolden SL, Steinherz PG, La Quaglia MP. Factors associated with relapse and survival in Wilms tumor: A multivariate analysis. J Pediatr Surg. 2012;47:1228-33.

3. Scott RH, Murray A, Baskcomb L, Turnbull C, Loveday C, AlSaadi R, Williams R, Breatnach F, Gerrard M, Hale J, Kohler J, Lapunzina P, Levitt GA, Picton S, Pizer B, Ronghe MD, Traunecker H, Williams D, Kelsey A, Vujanic GM, Sebire NJ, Grundy P, Stiller CA, Pritchard-Jones K, Douglas J, Rahman N. Stratification of Wilms tumor by genetic and epigenetic analysis. Oncotarget. 2012;3:327-35.

4. Diniz G, Aktas S, Cubuk C, Ortac R, Vergin C, Olgun N. Tissue expression of MLH1, PMS2, MSH2, and MSH6 proteins and prognostic value of microsatellite instability in Wilms tumor: Experience of 45 cases. Pediatr Hematol Oncol. 2013;30:273-84.

5. Kjeldsen L, Johnsen AH, Sengeløv H, Borregaard N. Isolation and primary structure of NGAL, a novel protein associated with human neutrophil gelatinase. J Biol Chem. 1993; 268:10425-32.

6. Bratt T. Lipocalins and cancer. Biochim Biophys Acta. 2000;1482:318-26.

7. Bolignano D, Donato V, Lacquaniti A, Fazio MR, Bono C, Coppolino G, Buemi M. Neutrophil gelatinase-associated lipocalin (NGAL) in human neoplasias: A new protein enters the scene. Cancer Lett. 2010;288:10-6.

8. Ichimura $\mathrm{T}$, Bonventre JV, Bailly $\mathrm{V}$, Wei $\mathrm{H}$, Hession CA, Cate RL, Sanicola M. Kidney injury molecule-1 (KIM-1), a putative epithelial cell adhesion molecule containing a novel immunoglobulin domain, is up-regulated in renal cells after injury. J Biol Chem. 1998;273:4135-42.

9. Zhang PL, Mashni JW, Sabbisetti VS, Schworer CM, Wilson GD, Wolforth SC, Kernen KM, Seifman BD, Amin MB, Geddes TJ, Lin F, Bonventre JV, Hafron JM. Urine kidney injury molecule-1: A potential non-invasive biomarker for patients with renal cell carcinoma. Int Urol Nephrol. 2014; 46:379-88.

10. Sinha V, Vence LM, Salahudeen AK. Urinary tubular proteinbased biomarkers in the rodent model of cisplatin nephrotoxicity: A comparative analysis of serum creatinine, renal histology, and urinary KIM-1, NGAL, and NAG in the initiation, maintenance, and recovery phases of acute kidney injury. J Investig Med. 2013;61:564-8.

11. Diniz G, Aktas S, Turedi A, Temir G, Ortac R, Vergin C. Telomerase reverse transcriptase catalytic subunit expression and proliferation index in Wilms tumor. Tumour Biol. 2011;32:761-7.

12. Horster MF, Braun GS, Huber SM. Embryonic renal epithelia: Induction, nephrogenesis, and cell differentiation. Physiol Rev. 1999;79:1157-91. 
13. Vicent S, Chen R, Sayles LC, Lin C, Walker RG, Gillespie AK, Subramanian A, Hinkle G, Yang X, Saif S, Root DE, Huff V, Hahn WC, Sweet-Cordero EA. Wilms tumor 1 (WT1) regulates KRASdriven oncogenesis and senescence in mouse and human models. J Clin Invest. 2010;120:3940-52.

14. Lanzkowsky P. Renal tumors. In: Manuel of pediatric hematology and oncology. $5^{\text {th }}$ ed. London: Elsevier; 2011. 695-714.

15. Tosun Yildirim H, Diniz G, Oymak Y, Demirağ B, Aktaş S, Ortaç R, Solakoğlu Kahraman D, Sayhan S, Hoşgör M. Caveolin-1 expression is associated with tumor size and therapy response in Wilms tumor. Turkiye Klinikleri J Med Sci. 2015;35:31-5.

16. Li SH, Hawthorne VS, Neal CL, Sanghera S, Xu J, Yang J, Guo H, Steeg PS, Yu D. Upregulation of neutrophil gelatinase-associated lipocalin by ErbB2 through nuclear factor-kappaB activation. Cancer Res. 2009;69:9163-8.

17. Kubben FJ, Sier CF, Hawinkels LJ, Tschesche H, van Duijn W, Zuidwijk K, van der Reijden JJ, Hanemaaijer R, Griffioen G, Lamers CB, Verspaget HW. Clinical evidence for a protective role of lipocalin-2 against MMP-9 autodegradation and the impact for gastric cancer. Eur J Cancer. 2007;43:1869-76.

18. Zhang H, Xu L, Xiao D, Xie J, Zeng H, Wang Z, Zhang X, Niu Y, Shen Z, Shen J, Wu X, Li E. Upregulation of neutrophil gelatinaseassociated lipocalin in oesophageal squamous cell carcinoma: Significant correlation with cell differentiation and tumour invasion. J Clin Pathol. 2007;60:555-61.
19. Volpe V, Raia Z, Sanguigno L, Somma D, Mastrovito P, Moscato F, Mellone S, Leonardi A, Pacifico F. NGAL controls the metastatic potential of anaplastic thyroid carcinoma cells. J Clin Endocrinol Metab. 2013;98:228-35.

20. Tung MC, Hsieh SC, Yang SF, Cheng CW, Tsai RT, Wang SC, Huang MH, Hsieh YH. Knockdown of lipocalin-2 suppresses the growth and invasion of prostate cancer cells. Prostate. 2013;73:1281-90.

21. Nuntagowat C, Leelawat K, Tohtong R. NGAL knockdown by siRNA in human cholangiocarcinoma cells suppressed invasion by reducing NGAL/MMP-9 complex formation. Clin Exp Metastasis. 2010;27:295-305.

22. Wang L, Chen C, Li F, Hua Q, Chen S, Xiao B, Dai M, Li M, Zheng A, Yu D, Hu Z, Tao Z. Down-regulation of neutrophil gelatinaseassociated lipocalin in head and neck squamous cell carcinoma correlated with tumorigenesis, not with metastasis. Int J Clin Exp Pathol. 2015;8:8857-68.

23. Ranghino A, Dimuccio V, Papadimitriou E, Bussolati B. Extracellular vesicles in the urine: Markers and mediators of tissue damage and regeneration. Clin Kidney J. 2015;8:23-30.

24. Cuadros T, Trilla E, Sarró E, Vilà MR, Vilardell J, de Torres I, Salcedo M, López-Hellin J, Sánchez A, Ramón y Cajal S, Itarte E, Morote J, Meseguer A. HAVCR/KIM-1 activates the IL-6/STAT-3 pathway in clear cell renal cell carcinoma and determines tumor progression and patient outcome. Cancer Res. 2014;74:1416-28. 